\title{
Knowledge of evolution and human diversity: a study among high school students of Rome, Italy
}

Fabrizio Rufo ${ }^{1,2^{*}}$, Marco Capocasa ${ }^{1,2}$, Veronica Marcari ${ }^{2}$, Enzo D'arcangelo ${ }^{3}$ and Maria Enrica Danubio ${ }^{4,2}$

\begin{abstract}
Background: This research investigated the knowledge of the complex concept of evolution in a sample $(n=1108)$ of final-year high school students of Rome. Particular attention was given to the evolution of Homo sapiens and to human diversity at the biological and cultural level. Obtained results were analysed in relation to the socio-cultural context of the students. The final objective of the research is to provide teachers, curriculum developers and policy makers with results on basic knowledge on evolution and human diversity of students who are to face the University.

Methods: The research was conducted using an ad hoc questionnaire in five scientific (Liceo scientifico) and four humanistic (Liceo classico) high schools of Rome. The research involved the final-year students, those who are supposed to have a global basic knowledge of cultural and biological aspects of the evolutionary theory. The research project, its aims and modes of realisation were presented and discussed in detail with Deans, teachers and students of the Institutions that volunteered to participate.
\end{abstract}

Results: The results show: (1) good knowledge and substantial acceptance of the evolutionary perspective; (2) that cultural and biological diversity are considered as decisive factors in modelling the present-day differences between human groups; (3) that, nonetheless, more than half the students still hold to a classificatory conception of human populations; (4) that the family cultural background is significantly relevant in the education of children.

Conclusions: Results of the research highlight some useful recommendations that should contribute to the work of teachers, curriculum developers and policy makers as they refer to what students have learned about evolution and human diversity. These results confirm the fundamental importance of investment in education.

Keywords: Knowledge of evolution, Human diversity, Main determinants, Rome

\section{Background}

The interpretation of the concept of evolution is characterised by wide links between very different research fields (Ayala 2008). The concept itself applies to many diversified phenomena, both at temporal and dimensional scales, as it deals with bacteria, plants, human populations or global ecological scenarios. In addition to a strictly biological context, the theoretical evolutionary framework has been successfully utilised for an understanding of cultural dynamics (Cavalli Sforza and Feldman 1981; Cavalli Sforza

\footnotetext{
*Correspondence: fabrizio.rufo@uniroma1.it

'Department of Biology and Biotechnology "Charles Darwin", Sapienza

University of Rome, Piazzale Aldo Moro 5, 00185, Rome, Italy

${ }^{2}$ Istituto Italiano di Antropologia, Rome, Italy

Full list of author information is available at the end of the article
}

2004). Therefore, knowledge of its acceptance and learning and of the factors of misunderstanding and misconceptions among youths, the human capital of the future, is of great interest. Indeed, the debate on the perception of evolutionary theory, instruction and learning (Woods and Scharmann 2001; Berkman et al. 2008; Donnelly et al. 2009; Thanukos et al. 2010) and on the factors of misunderstanding and misconceptions about acceptance and learning of evolution is very lively at the scholastic level (Shtulman et al. 2008; Sinatra et al. 2008; Cho et al. 2011).

Given the complexity of the concept applied to diversified phenomena and levels of human evolution (biological, metaphysical, cultural), the topic is of particular relevance in biological anthropology. To this purpose, Wescott and 
Cunningham 2005 conducted a survey of students enrolled in the 'Introduction to Biological Anthropology' course at the University of Missouri-Columbia aimed at analysing students" misconceptions about evolutionary theory and the strength of such misconceptions that are often reinforced by instructors, textbooks and popular media, all attempting to simplify the concepts. These authors further deepened their research by providing some methodological tools to help the students to recognize, revise and reorganize their knowledge and, thus, undergo conceptual change (Cunningham and Wescott 2009).

The present research investigated the issue of evolution and human diversity in a sample of high school students in Rome, Italy, by considering the results within the current institutional teaching framework. The project was funded by the Province of Rome as a case-study, the results of which are to be presented to the volunteering schools in order to update deans, teachers and students on their common work. The survey was conducted in the 2009 to 2010 school year in high schools in Rome, located in both the centre and outlying areas. Particular attention was given to topics related to (1) evolution of Homo sapiens and (2) human diversity, both at the biological and cultural level. Finally, the data were analysed and discussed in relation to the socio-cultural context of the individual students to evaluate the eventual role played by the familial mileu. The final objective of the research is to provide teachers, curriculum developers and policy makers with basic results on what students have learned about evolution and human diversity.

\section{The Italian educational context}

The Ministerial Act of 9 February 1979, introduced the teaching of evolutionary theory in Italian secondary school curricula as a topic in the 'Natural Sciences' (biology, chemistry and earth sciences). Introducing evolutionary theory in mandatory school curricula is important in correlating biological facts and phenomena, but also as an epistemological model for different disciplines. In February 2004, the Education Minister proposed a legislative decree to remove the teaching of evolution from the secondary school curriculum. The topics to be removed were 'Evolution of Earth', 'Appearance of life on Earth, 'Structure, function and evolution of living' and 'Origin and bio-cultural evolution of human species'. The mobilization of the Italian scientific community gave rise to a public petition to the Minister, aimed at asking the Minister to 'review the secondary schools programs and to rectify an oversight which is detrimental to the scientific culture of future generations' (Lorenzi 2004). The Darwin Commission, established in April 2004 and chaired by Nobel Prize winner Rita Levi Montalcini, delivered (February 2005) an official request to the Minister for the re-introduction of the teaching of evolution. This was accepted in October 2005 and resulted in a reviewed science curriculum for secondary school (Frazzetto 2004; Allgaier and Holliman 2006; Castellacci 2006; Pievani 2007).

Concerning primary schools, the teaching of the 'Earth before man' and of 'Prehistory' was introduced by the Ministerial National Guidelines (D.L. 19.02.2004) in third grade classrooms. However, the Guidelines do not mention teaching, e.g., evolution of living beings; it approaches 'biodiversity' and the comparison between natural and human history in a very general way (De Biase 2009; Berti et al. 2010).

Within the Italian high school system, the Liceo scientifico (scientific) and the Liceo classico (humanistic) are considered the more adequate to address the entrance requirements for university admission (Cecchi 2010). These curricula are structured in five years, and the teaching of the Natural Sciences in the humanistic curriculum totals 66 hours per year (two hours a week). In contrast, the scientific curriculum provides 66 hours per year in the first two years and 99 hours in the last three. The concept of evolutionary theory is introduced in the second year of both curricula. It is noteworthy that both ministerial programs mention the study of evolution without any indication of its application to the evolution of the human species. Moreover, together with the above, the number of hours devoted to the teaching of evolutionary theory is basically a personal choice of each teacher/ institution.

The analysis of textbooks shows that evolution is treated with varying breadth and depth depending on the school curriculum for which the book is planned (Rosa 2005). They appear to include more examples and laboratory activities for secondary schools, whereas those for high schools are more theoretical. They highlight rote learning and, thus, an uncritical assimilation of scientific concepts (Fierli and Fichera 2005; Bandiera 2006; Bandiera and Bruno 2006; Valente and Cerbara 2008).

\section{Methods}

The survey was conducted in five scientific (Liceo scientifico) and four humanistic (Liceo classico) high schools in Rome via an ad hoc questionnaire. These two specific curricula were selected because, according to Checchi (2010), they are those whose students have the highest probability of successfully completing their university studies. The research involved the final-year students, those who are expected to have a global basic knowledge of the cultural and biological aspects of evolutionary theory.

The research project, its aims and modes of realisation were presented and discussed in detail with deans, teachers and students of the institutions that volunteered to participate. This was undertaken in order to obtain permission from the deans to access the schools and the classrooms. 


\section{The sample}

The sample consisted of 1,108 students (51.1\% males, $48.9 \%$ females). Of the total participants, 728 were from the scientific high schools and 380 from the humanistic ones. This discrepancy results from the fact that the number of students enrolled in the former has progressively increased in the last few decades (ISTAT 2002; MIUR 2010) following the trends of biotechnological achievements.

\section{The questionnaire}

The questionnaire was developed, at first, in collaboration with two teachers, one from each of the two selected curricula, to obtain a detailed picture of the knowledge of the concepts of evolution and biological and cultural diversity. It consisted of 24 questions organized in four sections, each with six questions. The questions involved dichotomous and multiple choice answers (up to seven) of which only one was correct. The first section investigated the students' knowledge of the age of the Earth and the evolution of species. It was followed by a section concerning knowledge of the evolution of Homo sapiens. The third included questions on human biological and cultural diversity, while the fourth referred to the personal background of the interviewee: gender, school, preferred courses, preferred reading material and educational level of the parents.

The teachers of all the schools that volunteered were involved in the final draft of the questionnaire in order to verify the congruency of the proposed issues with the contents of the scholastic programs. Administration of the questionnaire was carried out by the teachers to assure mass participation and to ensure that its compilation took place in the conditions to which the students were accustomed.

\section{Statistical analysis}

Statistical analysis (SAS software, version 9.2, SAS Institute Inc., Cary, NC) was carried out in various phases and with different methods, as always occurs in transverse questionnaire investigations:

a) Data correction, analysis of the means, variability, frequency tables, recoding of the variables, graphics;

b) analysis of double and multiple contingency tables, in particular cross-linking the answer variables with the structural variables: gender, type of school (classical high school, scientific high school), preferred school courses (humanistic, scientific), preferred reading materials (newspapers/non-fiction books, novels/poems), frequency of reading for nonscholastic purposes (rarely, several times per month, several times per week), educational level of the parents (both university graduates, one a university graduate, at least one a high school graduate, neither one a high school graduate); c) construction of a quantitative indicator (overall score) able to summarize the correctness of the answers provided by the students to the various questions: 4 points were assigned to a correct answer, 0 points to a wrong answer and from one to 3 points based on a scale of consistency for the other answers;

d) verification and validation of the 'overall score' indicator via analysis of the distribution and comparison of the means for particular student subgroups. A second indicator based on the answers to the ten questions considered most informative from the semantic point of view was also calculated. The two indicators gave similar results under all aspects and the correlation between the overall score and the partial one was $0.79(P<0.0001)$. Therefore, the analyses based on the 'overall score' indicator refer to all the questions;

e) division of the 'overall score' variable into six classes $(P<60,60<P \leq 65,65<P \leq 70,70<P \leq 75,75<P \leq 80$, $P>80$ ) and analysis of the relationships between the score classes and structural variables;

f) multivariate analysis of the data. Firstly, different analysis of variance (ANOVA) models to study the variability of the 'overall score' (considered the response variable) as a function of the structural variables (considered covariates) were formalized; the aim was to assess possible differences in the means of the answers as a function of these variables, as an indicator of their influence on the attitudes of the students to evolution and human diversity. Both control variables (gender, type of school, parental educational level) and key predictor variables (preferred school courses, preferred reading material, frequency of reading) and their interactions were considered in the final selected ANOVA model.

\section{Results}

The $x^{2}$ test, applied to all contingency tables concerning cross-linking between answers to the various questions and gender of the interviewees, never revealed significant differences. Therefore, the following analyses considered the whole sample of interviewees. Results for each of the four sections of the questionnaire are reported.

Frequencies and percentages of response for each of the multiple choice options for each question are available electronically in Additional file 1. Table 1 summarizes these data in order to have an exhaustive synthetic overview.

\section{Section 1. Age of the earth and evolution of species}

Most of the students had a good knowledge of the evolution of species: $96.5 \%$ of them agreed with the existence of an evolutionary process underlying present-day 
Table 1 Results referring to the first three sections of the questionnaire (in percentages)

\begin{tabular}{|c|c|c|c|}
\hline Question & Correct & Wrong & No reply \\
\hline \multicolumn{4}{|l|}{ Section 1. Age of the Earth and evolution of species } \\
\hline For how many years has the Earth existed? & 86.6 & 9.8 & 3.6 \\
\hline What does 'biodiversity' mean? & 96.5 & 3.1 & 0.4 \\
\hline Were there species that lived in the past but which are now extinct? & 93.7 & 4.7 & 1.6 \\
\hline Have living forms always been as they are now & 96.5 & 3.1 & 0.4 \\
\hline Are there species living today which did not exist in the past & 93.7 & 4.7 & 1.6 \\
\hline Can environment conditions undergo profound changes over long periods of time? & 96.5 & 2.4 & 1.1 \\
\hline \multicolumn{4}{|l|}{ Section 2. Evolution of Homo sapiens } \\
\hline How many years ago did Homo sapiens appear & 33.0 & 53.5 & 13.5 \\
\hline Where did Homo sapiens first appear? & 69.9 & 24.1 & 6.0 \\
\hline Did physical characteristics of Homo sapiens change since it began to migrate into different environments? & 95.0 & 3.4 & 1.6 \\
\hline Is there fossil evidence documenting the places and times of the appearance of Homo sapiens? & 94.2 & 2.9 & 2.9 \\
\hline Does it make sense to speak & 29.8 & 70.2 & 0.0 \\
\hline Section 3. Human diversity & Yes & No & \\
\hline Did intellectual superiority contribute to the success of the great civilizations? & 57.1 & 42.9 & \\
\hline Did intellectual superiority contribute to scientific- technological progress? & 65.9 & 34.1 & \\
\hline Does intellectual superiority exist? & 7.4 & 92.6 & \\
\hline Does human diversity depend on biological and/or cultural factors? & 44.2 & 55.8 & \\
\hline Do you positively value contact between different cultures? & 92.6 & 7.4 & \\
\hline Has scientific progress helped to improve contacts between cultures? & 97.0 & 3.0 & \\
\hline
\end{tabular}

animal and plant biodiversity and with the interaction between living organisms and the surrounding environment in the evolutionary process; $93.7 \%$ interpreted this process on the basis of events such as extinction and speciation. Results for the age of the Earth were less precise; although $86.6 \%$ correctly answered the question, almost $10 \%$ provided wrong answers.

\section{Section 2. Evolution of Homo sapiens}

To the first question of this section (not included in Table 1) on whether modern man is the fruit of an evolutionary process or a creation event, $97.2 \%$ of students gave the first choice. The remaining questions and answers show that almost the entire sample $(94.2 \%)$ was aware that the discovery of fossil remains has allowed scientists to understand the times and places of the appearance of man on Earth and 95\% interpreted the evolutionary changes in relation to adaptation to the environment in the course of the demic expansion of Homo sapiens from Africa to Middle Eastern regions.

The correctness of the answers decreased when the questions dealt with specific topics of human evolution. Only $69.9 \%$ of students considered Africa the origin of human species. Moreover, although only 33\% believed that human beings originated from an African population at the end of the middle Pleistocene around 150,000 years ago, $7.7 \%$ believed that Homo sapiens appeared one billion years ago, $11.1 \%$ one hundred million years ago, $20.6 \%$ twenty million years ago and $14.1 \%$ six thousand years ago, while $13.5 \%$ did not give an answer.

The last question in this part of the questionnaire concerned 'human races' and their biological interpretation. Only $29.8 \%$ of students agreed on the non-existence of human races. However, it is important to analyse the data for those who gave incorrect answers to this question: $44.8 \%$ of students believed that the concept of 'human races' was supported by biological evidence, $18.5 \%$ preferred to give it a social connotation, 5.9\% associated it with political motivations and the remaining $1 \%$ with religious motivations.

\section{Section 3. Human diversity}

This part of the questionnaire dealt with knowledge of the biological and cultural diversity of mankind. Most of the sample (57.1\%) thought that the development of the great Mediterranean civilizations in historical times was favoured by a presumed intellectual superiority which, according to $65.9 \%$ of the students, also contributed to the scientific and technological progress of present-day Western populations. Nevertheless, the vast majority of students (92.6\%) denied the existence of populations more intelligent than others.

Many students (44.2\%) considered human diversity equally dependent on cultural and biological factors. Finally, more 
Table 2 Effects of socio-cultural factors on students' score (ANOVA model)

\begin{tabular}{lccc}
\hline Socio-cultural factors & DF & F Value & Pr $>$ F \\
\hline Control variables & 1 & 0.02 & 0.9025 \\
Gender & 1 & 4.64 & 0.0314 \\
High school type (HST) & 3 & 17.97 & $<0.0001$ \\
Parental educational level (PEL) & & & \\
Key predictor variables & 1 & 1.89 & 0.1697 \\
Preferred school courses (PSC) & 2 & 5.02 & 0.0068 \\
Preferred reading materials (PRM) & 2 & 4.82 & 0.0082 \\
Frequency of reading (FOR) & & & \\
Interactions & 1 & 5.73 & 0.0169 \\
PSC*HST & 2 & 3.71 & 0.0248 \\
PSC*FOR & 2 & 2.52 & 0.0811 \\
HST*PRM & 3 & 1.52 & 0.2074 \\
PSC*PEL & 6 & 1.15 & 0.2792 \\
PEL*FOR & & & \\
\hline
\end{tabular}

than $90 \%$ positively valued contact between different cultures $(92.6 \%)$, which according to $97 \%$ would be favoured by scientific progress.

\section{Section 4. Personal and scholastic background}

Much of the processing of the questionnaires was dedicated to analysis of overall scores obtained by the students. They ranged from 13 to 89 , with a median of 70: $50 \%$ of the students had a score between the first and third quartiles, $25.1 \%$ were below the first quartile and $24.9 \%$ above the third quartile. Therefore, it can be said that $75 \%$ of the students showed a good degree of knowledge of the concepts of evolution and human diversity.

Variability of the scores was analysed by considering gender, type of school, preferred courses, preferred reading material, frequency of extra-curricular reading and educational level of the parents as covariates (Table 2). Once again, gender did not significantly affect the correctness of answers or the results of the interactions among all considered variables in the model. High school type and parental educational level showed strong simple effects as well as interesting interactive effects. Within key predictor variables, preferred reading material, i.e. newspapers, non-fiction books or novels, and the frequency of extra-curricular reading had strong simple and interactive effects. Interestingly, preferred school courses did not show a significant simple effect but gave significant results when interacting only with high school type and frequency of reading.

The first two interactions of the five reported show statistically significant values. The following three as well as the other ten not reported have progressively increasing values of $\operatorname{Pr}>\mathrm{F}$.

Contemporaneous consideration of preferred school courses and high school type, on one side, and frequency of reading, on the other, increased the significance of the differences in the scores. The remaining thirteen performed interactions never showed statistical significance.

Details of the above results are reported in Table 3. Interestingly, students attending a classical high school and preferring scientific subjects had higher mean scores than students with other combinations, whose mean scores were very similar. The interaction between preferred school courses and frequency of reading resulted in a constant increase of the mean values of the students'

Table 3 Descriptive statistics of significant interactions

\begin{tabular}{|c|c|c|c|c|}
\hline \multirow[t]{2}{*}{ Interactions } & & \multirow[t]{2}{*}{$\mathrm{N}$} & \multicolumn{2}{|c|}{ Overall Score } \\
\hline & & & mean & s.d. \\
\hline Preferred school courses & High school type & & & \\
\hline Humanistic & Classical & 224 & 69.95 & 7.59 \\
\hline Scientific & Classical & 98 & 72.69 & 8.29 \\
\hline Humanistic & Scientific & 238 & 69.74 & 7.64 \\
\hline Scientific & Scientific & 430 & 69.67 & 8.03 \\
\hline Preferred school courses & Frequency of reading & & & \\
\hline Humanistic & Rarely & 50 & 67.58 & 8.26 \\
\hline Humanistic & Several times/month & 96 & 69.71 & 7.23 \\
\hline Humanistic & Several times/week & 316 & 70.24 & 7.57 \\
\hline Scientific & Rarely & 80 & 69.64 & 6.86 \\
\hline Scientific & Several times/month & 93 & 68.02 & 9.82 \\
\hline Scientific & Several times/week & 355 & 70.94 & 7.85 \\
\hline
\end{tabular}




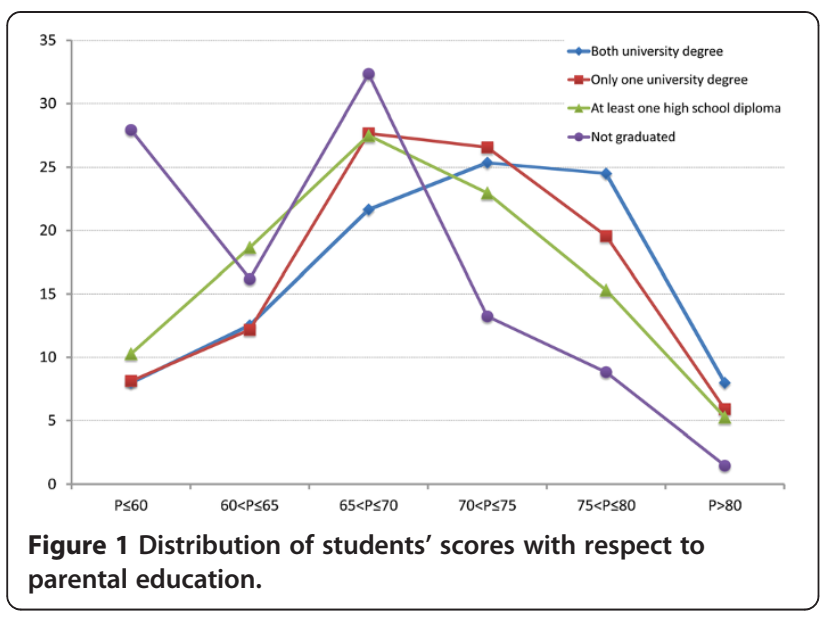

scores with increasing frequency of reading, the effect being higher in the case of students with humanistic interests.

The influence of the educational level of the parents, a highly significant variable, on the ability of their children to deal with the concepts of evolution and human biological and cultural diversity is underlined in this specific case. For $66.5 \%$ of the students with a score $>75$, at least one of the parents held a university degree, while $52.4 \%$ of the students with a score $\leq 65$ were children of parents whose highest educational level was high school graduation. Figure 1 illustrates the detailed pattern of the overall scores of students in relation to the four parental educational levels. The highest percentages of students with scores below the median value of 70 were children of parents with no more than a high school diploma. However, the percentages of those with scores above the median were distributed along a fairly regular gradient with respect to parental educational level. Moreover, it was mainly children of parents with a higher cultural background who did not believe that intellectual superiority favoured the development of the great civilizations and scientific progress (Table 4). They also represented the majority of the $33 \%$ who knew the date of the appearance of the human species and of the $29.8 \%$ who did not recognize any significance of the concept of 'human races'.

\section{Discussion}

The survey revealed good knowledge of the concept of evolution: the evolutionary process was perceived as a phenomenon requiring the conceptualization of 'deep time', in which natural history and human history do not coincide (Rossi 1984; Gee 1999). However, it is interesting that $53.5 \%$ of incorrect answers to the question on the chronology of the appearance of Homo sapiens included $14.1 \%$ by those believing that human species appeared only 6,000 years ago. Although this dating corresponds to the biblical chronology of creation, it seems more plausible that this part of the sample confused the origin of Homo sapiens with the birth of the great historical civilizations (AssyrianBabylonian, Sumerian, Egyptian). This interpretation is supported by the fact that only a small part of the sample (2.8\%) considered the appearance of the human species a creation event rather than an evolutionary process. This shows the acceptance of the evolutionary concept, despite the frequent attempts in recent years to revive creationist views (Miller et al. 2006; Blee and Creasap 2010).

Answers to the question on human races revealed that only $1 \%$ of the students considered religious motivations as the basis of the race concept. This result is only partially in line with the literature, as several studies have pointed out the link between religious affiliation and racial prejudice in different socio-cultural contexts (Altemeyer 2003; Campelli 2004; Hall et al. 2010). Indeed, the use of religion as a proxy in identifying racial classification is an easy-to-choose ethnocentric view that opposes 'us' to 'them"'

Almost half of the students (44.9\%) considered the concept of 'human races' supported by scientific evidence. This is particularly relevant when considering the well established evidence of the extraordinary genetic homogeneity of Homo sapiens (Barbujani and Colonna 2010).

Table 4 Relation between parental educational level and student abilities on the topic of human evolution

\begin{tabular}{|c|c|c|c|}
\hline Question & At least one university graduate & At least one high school graduate & Neither a high school graduate \\
\hline \multicolumn{4}{|c|}{ Is scientific progress associated with a certain degree of intellectual superiority? } \\
\hline Yes & 60.5 & 71.3 & 87.0 \\
\hline No & 39.5 & 28.7 & 13.0 \\
\hline \multicolumn{4}{|c|}{ How long has Homo sapiens been present on the Earth? } \\
\hline 150 thousand years & 36.5 & 28.7 & 30.4 \\
\hline Other answer & 63.5 & 71.3 & 69.6 \\
\hline \multicolumn{4}{|c|}{ Does it make sense to speak about 'human races' } \\
\hline Yes & 68.2 & 72.7 & 73.9 \\
\hline No & 31.8 & 27.3 & 26.1 \\
\hline
\end{tabular}


Human beings, descendants of a small number of ancestors, have continuously mixed in the course of their evolutionary history and the existing differences have been distributed in a continuous manner in geographical space. This renders the concept of race, and any consequent pretension of racial superiority, scientifically inconsistent (Barbujani et al. 1997; Rosenberg et al. 2002; Destro-Bisol et al. 2010; Rosa and Brehm 2011).

A social connotation was given to 'human races' by $18.5 \%$ of the students, probably because this term is often used to highlight differences related to ethnic identity and geographical origins. This seems to reveal a contradiction between comprehension of the evolutionary perspective and the persistence of a common belief deeply rooted in Western culture in the 19th and 20th centuries (Gould 1981; Pievani 2012). This belief is expressed from the biological point of view by the concept of race and from the cultural point of view by the distinction between ethnic groups.

Therefore, particular attention was given to the investigation of the knowledge of basic concepts of human biological and cultural diversity. Indeed, this is a decisive aspect, which stems from the theory by which culture, namely the set of meanings with which human beings interpret their experience and guide their actions (Geertz 1973), plays a role closely correlated to that of genetic processes in modelling evolution and, accordingly, the differences between human groups (Richerson and Boyd 2005; Laland et al. 2010). Cultural and biological diversity seem to be perceived by most students as decisive factors modelling the differences between human groups. Although for most students scientific progress has helped to improve cultural exchanges, it is still necessary to emphasize that more than half of them still evoke a classificatory conception of human populations according to which the success of great civilizations depended on superior intellectual abilities. Yet, this contrasts with the fact that almost all the sample affirmed the non-existence of intellectual superiority. This incongruity can be attributed to the fact that the students may have considered intellectual abilities common to all populations, interpreting the success of a civilization as determined by the attainment of specific socio-cultural conditions in a certain historical period. Recent research in cognitive development suggests the tendency to emphasize the differences among human groups, rather than within group diversity (Opfer et al. 2012; Beggrow and Nehm 2012). There is concern that such cognitive biases (e.g., appeal of teleology and emotiinal reactions to human diversity) may prevent students' full understanding of the epistemological foundations of human diversity (Girotto et al. 2008; Shtulman and Calabi 2013). In fact, predisposition for common-sense intuitions about physical and psychological domains can contribute to the resistance of the acceptance of scientific information (Bloom and Skolnick Weisberg 2007; Gonzalez Galli and Meinardi 2011).

The last part of the questionnaire, concerning the personal background of the students, allowed us to investigate potential interactions between socio-cultural factors and the degree of knowledge of evolution and diversity (Pingree et al. 2000). A first result was that students' overall scores did not show substantial gender differences. This is important in a context such as that of the city of Rome, capital of a country where marked inequality of genders persists even today (Mills et al. 2008; Costantini and Monni 2009; Campa et al. 2011) and where, in the 1950 s, there were only 38,208 women among 145,000 university students (26.3\% of the total). Of these, only 12,736 (8.8\% of the total) choose a scientific faculty (ISTAT 1997). By comparison, in the University of Rome's 2009 to 2010 academic year, female students in the Faculty of Sciences made up 52\% of the total $(7,693$ of a total 14,792 students) (MIUR 2011).

The educational level of the parents was a highly significant structural variable, underlining the importance of the role of the family's cultural context in the education of children, a finding reported in many studies conducted in various sectors in both Italy (Checchi et al. 2006) and other European countries (Black et al. 2005; Daouli et al. 2010; Pereira 2010).

To summarize, the following main points should be stressed:

- When considering human diversity, students are able to interpret the differences between human groups as a result of the dual decisive action of both cultural and biological factors. As a consequence, almost all of them affirm the nonexistence of intellectual superiority. Nonetheless, when dealing with success of the great civilizations, more than half of the students still hold to a classificatory conception of human populations based on the existence of superior intellectual abilities. This incongruity gives evidence to the difficulty of linking biological evolution to the cultural progress of Homo sapiens, a rational animal. However, this is not surprising because this subject is not usually treated in Italian high schools, even though the scientific debate on the theory of the 'dual inheritance' of genetic and cultural traits has been developed over the last three decades (Feldman and Cavalli Sforza 1976; Boyd and Richerson 1985; Richerson and Boyd 2005; Laland et al. 2010).

- familial cultural background is important in the education of children and in the development of their cultural interests. Italy is an important case-study in 
this regard: two thirds of the Italian population never read a book or a newspaper (De Mauro 2010); in many areas of southern Italy, the problem of school leaving, especially among younger cohorts, is still very serious (Ballarino et al. 2010) and the percentage of Italian university graduates is also below the international mean (Benvenuto 2007); economic resources dedicated to cultural topics are minimal and only $4.6 \%$ of GDP is invested in education and research (De Mauro 2010). Despite the deep sociodemographic changes of the last decades in Italy, family remains the cornerstone of the social and economic structure. This strong family network can be traced by a series of indicators: the number of children over eighteen years old living in the household; geographical proximity of married children to the mother; financial support given by the parents to their children. All of this, often results in 'familism,' a specific relationship among family, civil society and the State, where the values and interests of the family are always preferred and opposed to any other momentum of human coexistence. This has no equal in any other European Country (Banfield 1958; Barbagli and Kertzer 1990; Ginsborg 2003; Barbagli et al. 2004).

\section{Conclusions}

In conclusion, the results of this research highlight some useful recommendations that should contribute to the work of teachers, curriculum developers and policy makers as they refer to what students have learned about evolution and human diversity.

Indeed, it would be necessary to better define and develop the institutional guidelines by:

1) increasing the number of teaching hours devoted to 'Natural Science' with the introduction and/or implementation of laboratory activities in classrooms that would help in fixing complex and counter-intuitive theoretical concepts;

2) specifically mentioning the teaching of evolutionary theory and its application to the evolution of human species and to the biological basis of human diversity. This would contribute to contrasting and preventing the diffusion of racism. This is an emerging topic in Italy, because the country is undergoing a profound and rapid transformation towards a multiethnic and multicultural society;

3) we highly recommend that the teaching of human evolution should be agreed upon between, and supported by, the teachers of science and humanities together. This would help the students to understand and solve the difficulty emerging from this research about linking biological evolution to the cultural progress of Homo sapiens;

4) specific mention at the institutional level should be given to the contents of science textbooks. In particular, they should necessarily include a wide section on human evolution and human biological diversity.

However, since this research refers to the city of Rome, a capital city, and since north/south and rural/urban socioeconomic differences are still diffuse in Italy, it is necessary to continue this research by monitoring different geographical and social situations in order to provide an exhaustive picture of the level of acquisition of these educational topics at the national level.

\section{Additional file}

Additional file 1: Full version of the questionnaire including

frequencies and percentages of the answers.

\section{Competing interests}

The authors declare that they have no competing interests.

\section{Authors' contributions}

FR designed the research; MC and VM collected the data; ED analysed the data; FR, MC and MC wrote the paper. All authors read and approved the final manuscript.

\section{Acknowledgements}

Research funds were made available by the Province of Rome. Particular gratitude goes to all the students for their enthusiasm and seriousness in answering the questionnaires. The authors wish to thank all those who contributed to the survey, in particular the headmasters and teachers of the following Roman high schools: Liceo Classico e Linguistico Statale Aristofane, Liceo Scientifico Statale Aristotele, Liceo Scientifico Statale Benedetto Croce, Liceo Scientifico Statale Antonio Labriola, Liceo Classico Statale Terenzio Mamiani, Liceo Scientifico Statale Nomentano, Liceo Scientifico Statale Plinio Seniore, Istituto di Istruzione Superiore Liceo Lucio Anneo Seneca, Liceo Ginnasio Statale Ennio Quirino Visconti. Special acknowledgements to Giorgio Narducci and Adam Goldstein for their useful comments on a previous draft of this manuscript.

\section{Author details}

'Department of Biology and Biotechnology "Charles Darwin", Sapienza University of Rome, Piazzale Aldo Moro 5, 00185, Rome, Italy. Istituto Italiano di Antropologia, Rome, Italy. ${ }^{3}$ Department of Statistical Sciences, Sapienza University of Rome, Rome, Italy. ${ }^{4}$ Department of Life, Health and Environmental Sciences, University of L'Aquila, L'Aquila, Italy.

Received: 23 April 2013 Accepted: 23 April 2013

Published: 21 July 2013

\section{References}

Allgaier, J, \& Holliman, R. (2006). The emergence of the controversy around the theory of evolution and creationism in UK newspaper reports. Curric J, $17(3), 263-279$

Altemeyer, B. (2003). Why do religious fundamentalists tend to be prejudiced? Int J Psychol Relig, 13, 17-28.

Ayala, FJ. (2008). Science, evolution, and creationism. Proc Natl Acad Sci USA, 105, 3-4.

Ballarino, G, Checchi, D, Fiorio, C, \& Leonardi, M. (2010). Le disuguaglianze nell'accesso all'istruzione in Italia. Quaderni Rassegna Sindacale-Lavori, 11(1), 177-231 
Bandiera, M. (2006). La formazione scientifica nell'esperienza di un insegnante. In C Mangia, P Colella, A Lanotte, G Gioia, \& D Grasso (Eds.), Donne, scienza e potere. Oseremo disturbare l'universo? (pp. 71-80). Lecce: Università degli Studi di Lecce.

Bandiera, M, \& Bruno, C. (2006). Active/cooperative learning in schools. J Biol Educ, 40(3), 130-134.

Banfield, EC. (1958). The moral basis of a backward society. Glencoe: The Free Press.

Barbagli, M, Castiglioni, M, \& Dalla, ZG. (2004). Fare famiglia in Italia. II Mulino: Un secolo di cambiamenti. Bologna.

Barbagli, M, \& Kertzer, D. (1990). An introduction to the history of the Italian family. J Fam Hist, 15, 369-384.

Barbujani, G, \& Colonna, V. (2010). Human genome diversity: frequently asked questions. Trends Genet, 26(7), 285-295.

Barbujani, G, Magagni, A, Minch, E, \& Cavalli-Sforza, LL. (1997). An apportionment of human DNA diversity. Proc Natl Acad Sci USA, 94(9), 4516-4519.

Beggrow, EP, \& Nehm, RH. (2012). Students' mental models of evolutionary causation: natural selection and genetic drift. Evolution: Education and Outreach, 5, 429-444.

Benvenuto, G. (2007). Dispersione scolastica e universitaria. Economia \& Lavoro, 41(1), 77-94.

Berkman, MB, Sandell Pacheco, J, \& Plutzer, E. (2008). Evolution and creationism in America's classrooms: a national portrait. PLoS Biol, 6(5), 920-924.

Berti, AE, Toneatti, L, \& Rosati, V. (2010). Children's conceptions about the origin of species: a study of italian children's conceptions with and without Instruction. J Learn Sci, 19, 506-538.

Black, SE, Devereux, PJ, \& Salvanes, KG. (2005). Why the apple doesn't fall far: understanding intergenerational transmission of human capital. Am Econ Rev, 95(1), 437-449.

Blee, KM, \& Creasap, KA. (2010). Conservative and right-wing movements. Annu Rev Sociol, 36, 269-286.

Bloom, P, \& Skolnick Weisberg, D. (2007). Childhood origins of adult resistance to science. Science, 316, 996-997.

Boyd, R, \& Richerson, P. (1985). Culture and The Evolutionary Process. Chicago: University of Chicago Press.

Campa, P, Casarico, A, \& Profeta, P. (2011). Gender culture and gender gap in employment. CESifo Economic Studies, 57(1), 156-182.

Campelli, E. (2004). Figli di un dio locale. Giovani e differenze culturali in Italia. Milano: Franco Angeli.

Castellacci, C. (2006). II male e il rimedio: riflessioni sull'affare Darwin-Moratti. J Sci Commun, $5,2$.

Cavalli Sforza, LL. (2004). L'Evoluzione della cultura. Torino: Codice Edizioni.

Cavalli Sforza, LL, \& Feldman, MW. (1981). Cultural transmission and evolution: a quantitative approach. Princeton: Princeton University Press.

Checchi, D. (2010). Percorsi scolastici e origini sociali nella scuola italiana. Politica Economica, 24(3), 359-387.

Checchi, D, Fiorio, CV, \& Leopardi, M. (2006). Sessanta anni di istruzione in Italia. Rivista di Politica Economica, 7, 285-318.

Cho, MH, Lankford, DM, \& Wescott, DJ. (2011). Exploring the relarionships among epistemological beliefs, nature of science, and conceptual change in the learning of evolutionary theory. Evolution: Education and Outreach, 4, 313-322.

Costantini, V, \& Monni, S. (2009). Gender disparities in the Italian regions from a human development perspective. Journal of Socio-Economics, 38(2), 256-269.

Cunningham, DL, \& Wescott, DJ. (2009). Still more "fancy" and "myth" than "fact" in students' conceptions of evolution. Evolution: Education and Outreach, 2, 505-517.

Daouli, J, Demoussis, M, \& Giannakopoulos, N. (2010). Mothers, fathers and daughters: intergenerational transmission of education in Greece. Econ Educ Rev, 29(1), 83-93.

De Biase, I. (2009). Comunicare la Storia Naturale dell'Uomo: Ombre e Luci. Antrocom-Online Journal of Anthropology, 5(1), 73-78.

De Mauro, T. (2010). La cultura degli Italiani. Roma-Bari: Laterza.

Destro-Bisol, G, Jobling, MA, Rocha, J, Novembre, J, Richards, MB, Mulligan, C, Batini, C, \& Manni, F. (2010). Molecular anthropology in the genomic era. $J$ Anthropol Sci, 88, 93-112.

Donnelly, LA, Kazempour, M, \& Amirshokoohi, A. (2009). High school students' perceptions of evolution instruction: acceptance and evolution learning experiences. Res Sci Educ, 39, 643-660.

Feldman, MW, \& Cavalli Sforza, LL. (1976). Cultural and biological evolutionary processes, selection for a trait under complex transmission. Theor Popul Biol, $9(2), 238-259$
Fierli, M, \& Fichera, A. (2005). La scienza nei libri di testo della scuola di base. In N Pitrelli, G Sturloni (Eds.), La Stella Nova. Atti del III Convegno Annuale sulla Comunicazione della Scienza (pp. 105-118). Monza: Polimetrica International Scientific Publisher.

Frazzetto, G. (2004). Who's afraid of Darwin? EMBO Rep, 5(7), 662-665.

Gee, H. (1999). In search of deep time: beyond the fossil record to a new history of life. New York: Free Press.

Geertz, C. (1973). The interpretation of cultures. New York: Basic Books.

Ginsborg, P. (2003). A history of contemporary Italy: society and politics, 1943-1988. London: MacMillan

Girotto, V, Pievani, T, \& Vallortigara, G. (2008). Nati per credere. Perché il nostro cervello sembra predisposto a fraintendere la teoria di Darwin. Torino: Codice.

Gonzalez Galli, L, \& Meinardi, EN. (2011). The role of teleological thinking in learning the Darwinian model of evolution. Evolution: Education and Outreach, 4, 145-152.

Gould, SJ. (1981). The mismeasure of man. New York: Norton.

Hall, DL, Matz, DC, \& Wood, W. (2010). Why don't we practice what we preach? A meta-analytic review of religious racism. Personality and Social Psychology Review, 14(1), 126-139.

ISTAT. (1997). Statistiche dell'istruzione universitaria: anno accademico 1995-96. Roma: ISTAT.

ISTAT. (2002). Statistiche delle scuole secondarie superiori anno scolastico 1998-99. Annuario n.10. Roma: ISTAT.

Laland, KN, Odling-Smee, J, \& Myles, S. (2010). How culture shaped the human genome: bringing genetics and the human sciences together. Nat Rev Genet, $11,137-148$.

Lorenzi, R. (2004). No evolution for Italian teens. The Scientist. http://www.thescientist.com/?articles.view/articleNo/22817/title/No-evolution-for-Italianteens/. Accessed 28 Mar 2013.

Miller, JD, Scott, EC, \& Okamoto, S. (2006). Science communication: public acceptance of evolution. Science, 313, 765-766.

Mills, M, Mencarini, L, Tanturri, ML, \& Begal, K. (2008). Gender equity and fertility intentions in Italy and the Netherlands. Demogr Res, 18(1), 1-26.

MIUR. (2010). Focus in breve sulla scuola: le iscrizioni alla nuova scuola superiore A.S. 2010/2011. Roma: Direzione Generale per gli Studi, la Statistica e per i Sistemi Informativi - Servizio Statistico.

MIUR. (2011). Indagine sullistruzione universitaria. http://statistica.miur.it/scripts/IU/ vIU1.asp. Accessed 28 Mar 2013.

Opfer, JE, Nehm, RH, \& Ha, M. (2012). Cognitive foundations for science assessment design: knowing what students know about evolution. J Res Sci Teach, 49(6), 744-777.

Pereira, PT. (2010). Low educational attainment in Portugal - intergenerational transmission of a big problem. Investigaciones de Economía de la Educación, $5,36-46$.

Pievani, T. (2007). In difesa di Darwin. Milano: Bompiani.

Pievani, T. (2012). Many ways to being human, the Sephen J. Gould's legacy to paleo-Anthropology (2002-2012). J Anthropol Sci, 90, 133-149.

Pingree, S, Hawkins, RP, \& Botta, RA. (2000). The effect of family communication patterns on young people's science literacy. Sci Commun, 22, 115-132.

Richerson, PJ, \& Boyd, R. (2005). Not by genes alone: how culture transformed human evolution. The Chicago: University of Chicago Press.

Rosa, R. (2005). L'evoluzione nei libri di testo e nei programmi di insegnamento. Italy: Atti del XIII Incontro Annuale di Studi del Gruppo Italiano di Biologia Evoluzionistica.

Rosa, A, \& Brehm, A. (2011). African human mtDNA phylogeography at-a-glance. $J$ Anthropol Sci, 89, 25-58.

Rosenberg, NA, Pritchard, JK, Weber, JL, Cann, HM, Kidd, KK, Zhivotovsky, LA, \& Feldman, MW. (2002). Genetic structure of human populations. Science, 298, 2381-2385

Rossi, P. (1984). The Dark Abyss of Time. Chicago: The University of Chicago Press.

Shtulman, A, \& Calabi, P. (2008). Learning, understanding, and acceptance: the case of evolution. In BC Love, K McRae, \& VM Sloutsky (Eds.), Proceedings of the 30th Annual Conference of the Cognitive Science Society (pp. 235-240). Austin: Cognitive Science Society.

Shtulman, A, \& Calabi, P. (2013). Tuition vs. intuition: effects of instruction on naïve theories of evolution. Merrill-Palmer Quarterly, 59(2), 141-167.

Sinatra, GM, Brem, SK, \& Evans, EM. (2008). Changing minds? implications of conceptual change for teaching and learning about biological evolution. Evolution: Education and Outreach, 1, 189-195. 
Thanukos, A, Scotchmoor, JG, Caldwell, R, \& Lindberg, DR. (2010). Science 101: building the foundations for real understanding. Science, 330, 1764-1765.

Valente, A, \& Cerbara, L. (2008). Percezione della scienza ed educazione scientifica nelle scuole. Roma: Istituto di Ricerche sulla Popolazione e le Politiche Sociali del CNR.

Wescott, DJ, \& Cunningham, DL. (2005). Recognizing student misconceptions about science and evolution. MountainRise, 2, 2. http://mountainrise.wcu.edu/index. php/MtnRise/article/view/60/69. Accessed 2 Apr 2013.

Woods, CS, \& Scharmann, LC. (2001). High school students' perceptions of evolutionary theory. Electron J Sci Educ, 6(2), 1-20.

doi:10.1186/1936-6434-6-19

Cite this article as: Rufo et al:: Knowledge of evolution and human

diversity: a study among high school students of Rome, Italy.

Evolution: Education and Outreach 2013 6:19.

Submit your manuscript to a SpringerOpen ${ }^{\circ}$ journal and benefit from:

- Convenient online submission

- Rigorous peer review

- Immediate publication on acceptance

- Open access: articles freely available online

- High visibility within the field

- Retaining the copyright to your article

Submit your next manuscript at $\gg$ springeropen.com 